\title{
Skema Alokasi Biaya Promosi Kesehatan untuk Mengendalikan DM di Kabupaten Sleman: Studi Kasus
}

\author{
Mahendro Prasetyo Kusumo ${ }^{1}$ dan Wisnu Murti Yani²
}

\author{
${ }^{1}$ Department of Public Health Faculty of Medicine and Health Sciences, \\ Universitas Muhammadiyah Yogyakarta \\ 2Sleman Health Office, Regional Government of Sleman Regency, Daerah Istimewa Yogyakarta \\ mahendro_prasetyo@umy.ac.id ${ }^{1}$
}

\author{
Diajukan 15 Juli 2021 Diperbaiki 24 November 2021 Diterima 24 November 2021 \\ ABSTRAK
}

Latar Belakang: Program promosi kesehatan (Promkes) menjadi kunci utama dalam mengendalikan Diabetes Melitus (DM) di Indonesia. Rendahnya alokasi biaya Promkes menjadi salah satu penyebab meningkatnya prevalensi DM, termasuk di Daerah Istimewa Yogyakarta (DIY). Kabupaten Sleman memiliki prevalensi DM tertinggi setelah Kota Yogyakarta.

Tujuan: Mengidentifikasi skema alokasi biaya Promkes di Kabupaten Sleman untuk mengendalikan DM di Kabupaten Sleman.

Metode: Penelitian ini adalah kualitatif dengan desain studi kasus. Partisipan terdiri dari lima pemangku kebijakan di Kabupaten Sleman. Pengumpulan data dengan observasi, wawancara dan studi dokumentasi. Triangulasi dan member checking dilakukan untuk validasi data kualitatif.Analisis data dilakukan menggunakan open code.

Hasil: Analisis data menghasilkan koding penting yang diidentifikasi dan dikelompokkan menjadi tiga domain, yaitu: 1) implementasi program Promkes 2) skema alokasi dana Promkes, dan 3) sumber pembiayaan Promkes. Prosedur pengajuan dana kegiatan Promkes rumit dan tidak jelas. Perlu disosialisasikan tata cara pengajuan biaya Promkes di setiap fasilitas pelayanan kesehatan primer. Selain itu, diperlukan strategi untuk mengajukan pembiayaan Promkes di Kabupaten Sleman melalui APBN, APBD, DAK, bagi hasil pajak dan dana desa.

Kesimpulan: Skema alokasi biaya Promkes untuk mengendalikan DM di Kabupaten Sleman dapat dilakukan melalui pengajuan dari Puskesmas. Alokasi dana tersebut bersumber dari APBN, APBD, DAK, bagi hasil pajak, dan dana desa.

Kata Kunci: DM; skema biaya promosi kesehatan; sumber biaya kesehatan

\section{ABSTRACT}

Background: Health promotion programs(Promkes) are the main key to controlDM in Indonesia. The lack of funds for Promkes is one of the causes the increasing of DM, including in Daerah Istimewa Yogyakarta (DIY). Sleman Regency is the highest prevalence of DM after Yogyakarta City.

Objective: Identifying Promkes cost allocation schemes in Sleman to control DM in Sleman.

Methods: This research is qualitative with a case study design. The participants consisted of five policymakers in Sleman Regency, Yogyakarta. Collecting data by observation, interviews, and documentation studies. Triangulation and member checking were carried out to validate qualitative data. Data analysis was performed using open code.

Results: The results of data analysis resulted in important coding that was identified and grouped into three domains: 1) implementation of Promkes in Sleman district 2) Promkes fund allocation schemes, and 3) Promkes financing sources. Procedures for applying Promkes activities funds are complex and unclear. It is necessary to socialize the procedures for submitting Promkes costs in each primary health service facility. In addition, a strategy is needed to apply for Promkes financing in Sleman district through the APBN, APBD, DAK, tax revenue sharing and village funds.

Conclusion: The scheme for the allocation of Promkes costs for controlling DM in Sleman district can be done through submissions from primary health service facilities. The allocation of these funds is sourced from the $A P B N, A P B D, D A K$, tax revenue sharing and village funds.

Keywords: DM; health promotion fee scheme; health cost source 
PENDAHULUAN

Secara global penyakit tidak menular (PTM) menjadi salah satu penyebab utama kematian. World Health Organization (WHO) melaporkan sebanyak 36 juta dari 57 juta kematian di dunia disebabkan oleh PTM (WHO, 2010). Diabetes Mellitus (DM) merupakan PTM yang prevalensinya terus meningkat. Rendahnya faktor ekonomimenyebabkan sulitnya untuk membeli dan mengolah makanan sehat. Selain itu, sebagian besar pasien PTM tidak memahami cara melakukan aktivitas fisik sesuai rekomendai WHO (Epstein and LaPorte, 2016).

Indonesia memiliki prevalensi DM tertinggi nomor 4 (8,4 juta jiwa) di duniadandiprediksi terus meningkat menjadi 21,3 juta jiwa pada tahun 2030 (Wild et al., 2004).

Pada tahun 2018, Pemerintah Indonesia melaporkan bahwa Provinsi Daerah Istimewa Yogyakarta (DIY) menduduki prevalensi tertinggi kedua DM, yaitu sebesar 2,6\% (RISKESDAS, 2018). Sebagian besar pasien tersebut tinggal di Kota Yogyakarta dan Kabupaten Sleman (Dinas Kesehatan Provinsi DIY, 2013). Sulitnya mengurangi kebiasaan mengkonsumsi makanan yang manis menjadi masalah utama meningkatnya DM di DIY (Kusumo, Hendrartini, Sufro and Dewi, 2020a).

Pemerintah Indonesia telah mencanangkan Program prolanis yang fokus mengendalika DM dan hipertensi. Kegiatan dari program tersebut adalah konsultasi medis atau edukasi, home visit, reminder, aktifitas klub dan pemantauan status kesehatan. Sumber pembiayaan program tersebut adalah dari BPJS Kesehatan (Badan Penyelenggara Jaminan Sosial, 2014).

Hasil penelitian sebelumnya juga menjelaskan bahwa masih terbatasnya manajemen PTM juga menjadi penyebab masih tingginya prevalensi DM (Grover and Joshi, 2015). Model pemantauan pasien DM untuk meningkatkan status kesehatan menjadi pilihan dalam menurunkan prevalensi DM (Siminerio, Zgibor and Solano, 2004; Grover and Joshi, 2015). Berbagai program telah dilakukan untuk mengurangi prevalensi DM dan komplikasinya, walaupun belum berhasil. Kecilnya alokasi biaya promotif dan prefentif menjadi salah satu penyebab semakin tingginya DM dan komplikasinya. Penelitian ini bertujuan untuk mengidentifikasi skema alokasi biaya promosi kesehatan dalam mengendalikan DM.

\section{METODE}

Penitian ini menggunakan metode kualitatif dengan desain studi kasus. Penelitian dilakukan pada bulan Juni sampai Agustus 2020 di Fasilitas Kesehatan Promer Kabupaten Sleman Provinsi Daerah Yogyakarta (DIY).Peneliti mengeksplorasi semua kejadian penting tentang skema dan sumber dana yang digunakan untuk melaksanakan program promosi kesehatan di Kabupaten Sleman. Disain penelitaian ini disesuaikan dengan panduan Consolidated Criteria for Reporting Qualitatif Research (COREQ).

Pemilihanpartisipan dilakukan dengan teknik purposive, yaitu dengan criterion sampling. Partisipanyang dipilih adalah orang yang dianggap mewaliki informasi yang dibutuhkan dan sesuai dengan tujuan penelitian.Partisipan tersebut terdiri dari lima pemangku kebijakan yang berperan penting dalam mengimplementasikan biaya promosi kesehatan di Kabupaten Sleman. Partisipan yang dipilih adalah orang yang mampu memberikan informasitentang skema dan sumber biaya promosi kesehatan, termasuk kendala yang dihadapa ketika mengajukan biaya promosi kesehatan di fasilitas kesehatan primer untuk mengendalikan DM di Kabupaten Sleman. Proses awal yang dilakukan peneliti pada saat wawancara adalah mendatangi dan memperkenalkan 
Skema Alokasi Biaya Promosi Kesehatan untuk Mengendalikan DM...

diri kepada partisipan. Peneliti menjelaskan maksud dan tujuan wawancara. Partisipan yang menyatakan bersedia secara sukarela mengisi informed consent. Wawancara dilakukan sesuai dengan kesepakatan waktu dan tempat antara peneliti dan partisipan. Sedangkan observasi dilakukan dengan cara peneliti mendatangi langsung pelaksanaan program promosi kesehatan di Fasilitas Kesehatan Primer. Pada saat observasi, keberadaan peneliti tidak diketahui oleh partisipan. Hal ini dilakukan untuk meningkatkan validitas hasil penelitian.

Alat ukur yang digunakan adalah panduan wawancara dan panduan observasi. Metode pengumpulan data dilakukan secara sistematik, mulai dari: 1 ) observasi di Fasilitas Kesehatan Primer 2) wawancara mendalam dengan lima pemangku kebijakan Kabupaten Sleman, dan 3) studi dokumentasi dari pemerintah pusat dan pemerintah daerah. Analisis data kualitatif dilakukan dengan menggunakan software opencode. Data tersebut diperoleh dari wawancara dan observasi yang diolah melalui proses transkripsi, kemudian dianalisis secara kualitatif melalui proses koding, kategorisasi dan yang terakhir menentukan tema. Analisis datakualitatif dari hasil wawancara dan observasi menggunakan pedoman dari Hubermen dan Miles. Kesimpulan dari penelitian kualitatif ini adalah sekema biaya promosi kesehatan untuk mengendalikan DM di Kabupaten Sleman.

Penelitimenjamin hasil analisis data penelitian dapat dipercaya, dengan cara melakukan triangulasi, member checking dan peer debriefing. Member checking dilakukan dengan mengajukan pertanyaan melalui metode wawancara pada salah satu pegawai di layanan kesehatan primer yang bertanggungjawab dalam menjalankan program promosi kesehatan. Hal ini dilakukan untuk memastikan bahwa hasil analisis data sama dengan yang dimaksudkan oleh pemegang kebijakan.

\section{HASIL DAN PEMBAHASAN}

Berbagai koding penting yang dihasilkan dari analisis kualitatif diidentifikasi dan dikelompokkan menjadi 3 (tiga) domain, yaitu: 1) implementasi program promosi kesehatan di Kabupaten Sleman 2) skema alokasi dana promosi kesehatan, dan 3) sumber pembiayaan promosi kesehatan. Adapun uraian dari ketiga tersebut adalah sebagai berikut:

Tabel 1. Hasil Penelitian Kualitatif

\begin{tabular}{cll}
\hline No & \multicolumn{1}{c}{ Kategori } & Pembiayaan \\
\hline 1 & $\begin{array}{l}\text { Penyuluhan kesehatan } \\
\text { tentang DM, pemeriksaan } \\
\text { glukosa darah, dan home } \\
\text { visite. }\end{array}$ & $\begin{array}{l}\text { Implementasi } \\
\text { program }\end{array}$ \\
2 promosi \\
kesehatan. \\
Skema Dana Desa, Dana \\
Daerah, dan Dana & Skema alokasi \\
Pemerintah Pusat. & dana promosi. \\
3 APBN, APBD, DAK, bagi & Sumber \\
& hasil pajak dan dana desa & $\begin{array}{l}\text { Pembiayaan } \\
\text { promosi }\end{array}$ \\
& & kesehatan. \\
\hline
\end{tabular}

\section{Implementasi program promosi kesehatan}

Berbagaiprogram promosi kesehatan telah dilakukan di wilayah Kabupaten Sleman. Beberapa program promosi yang telah diimplementasikan adalah diantaranya perilaku hidup bersih dan sehat (PHBS), kawasan bebas rokok, dan PTM. Pemerintah Kabupaten Sleman mengupayakan berbagai program pengendalian PTM melalui penyuluhan dan pemeriksaan rutin setiap bulan yang diadakan disetiap padukuhan. Berikut kutipan pernyataan partisipan:

\footnotetext{
"Pelaksanaan kegiatan promosi kesehatan di fasilitas kesehatan primer dilakukan setiap bulan di rumah Pak dukuh, tapi...ya kadang petugas nya tidak datang....(Prempuan, 30 tahun, ketua Program Promosi kesehatan)"
}

Pemeriksaan rutin yang dilakukan, yaitu: pemeriksaan darah sederhana (asam urat, gula darah dan kolestrol), penimbangan berat badan dan pemeriksaan tekanan darah, termasuk 
layanan home visit. Kendala yang terjadi ketika pemeriksaan darah sederhana adalah kehabisan bahan habis pakai yang digunakan untuk pemeriksaan asam urat, gula darah dan kolestrol. Berikut kutipan pernyataan partisipan:

"Kita ya...apa ya...kadang sulit ya...karena dana yang ada sangat terbatas, sedangkan jumlah yang ingin periksa darah banyak. Kadang kita kehabisan juga (Prempuan, 55 tahun, Pimpinan Fasilitas Kesehatan Primer)"

\section{Skema alokasi dana promosi}

Ada dua skema dana promosi kesehatan yang dapat dilakukan di Kabupaten Sleman, yaitu skema APBN dan sema APBD. Puskesmas menyusun Rencana Kerja dan Anggaran (RKA) berdasarkan alokasi yang diterima dari Kabupaten atau Kota dan hasil RKA dikompilasi oleh Dinas Kesehatan kabupaten atau kota yang selanjutnya dibahas dalam Rencana Anggaran Pendapatan dan Belanja Pemerintah Daerah (RAPBD). Berikut kutipan pernyataan partisipan:

"Puskesmas diberi wewenang untuk mengajukan dana promosi kesehatan melalui Dinkes Sleman. Pengajuan dana tersebut di bahas ketika rapat anggaran pendapatan dan belanja Daerah (laki-laki, 58 tahun, Pimpinan Daerah)"

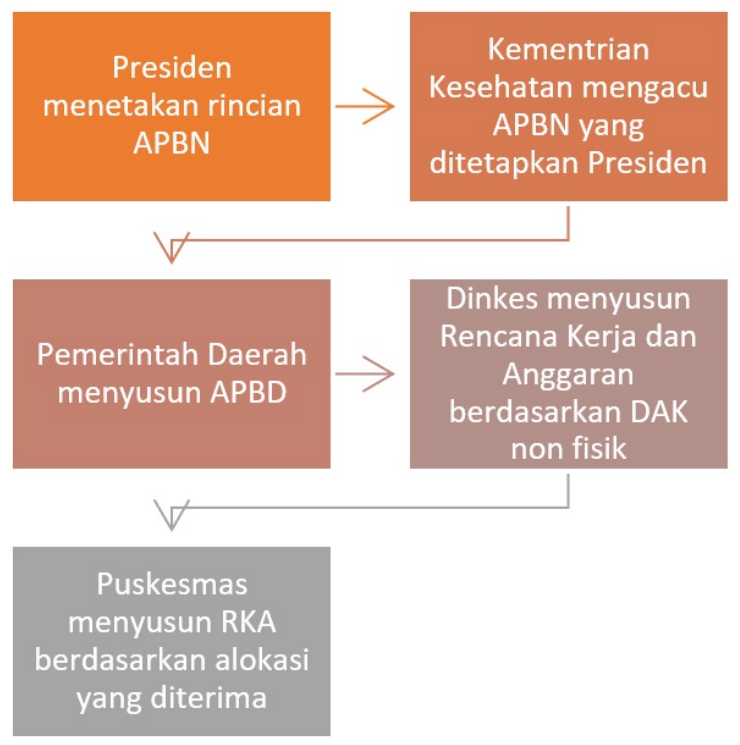

Pemerintah Daerah menganggarkan DAK Nonfisik Bidang Kesehatan ke Anggaran Pendapatan dan Belanja Daerah (APBD) dan atau APBD perubahan. Penyusunan rencana kegiatan Pemerintah Daerah penerima DAK Nonfisik Bidang Kesehatan mengacu pada rincian APBN yang ditetapkan oleh Presiden sesuai Perundang-undangan. Berikut kutipan pernyataan partisipan:

"Ya...Sumua dana kesehatan ditetapkan berdasarkan peraturan yang berlaku. Saat menyusun anggaran Kita mengacu pada $A P B N$ yang sudah ditetapkan oleh pemerintah pusat (laki-laki, 58 tahun, Pimpinan Daerah)"

Rencana kegiatan yang dilakukan harus memuat menu kegiatan, rincian alokasi DAK Nonfisik Bidang Kesehatan dan keterangan. Perubahan yang mengacu pada rincian alokasi DAK Non-fisik Bidang Kesehatan yang ditetapkan oleh Menteri. Pelaksanaan kegiatan DAK Nonfisik Bidang Kesehatan dilaksanakan oleh Dinkes Pemerintah Daerah Provinsi atau Kabupaten atau Kota sesuai kegiatan DAK Nonfisik Bidang Kesehatan masingmasing. Berikut kutipan pernyataan partisipan:

"Ada yang disebut DAK yang ditetapkan Mentri dan diimplementasikan oleh Dinkes Sleman (Prempuan, 48 tahun, kepala bidang)"

Pengelolaan DAK Nonfisik Bidang Kesehatan di daerah meliputi penyusunan, penganggaran, dan pelaksanaan, pelaporan, dan monitoring dan evaluasi. Pemerintah Daerah menyampaikan laporan realisasi DAK Nonfisik kepada Kementerian Kesehatan melalui E-renggar. Laporan dilakukan setiap triwulan, yang meliputirealisasipenyerapan anggaran, realisasi kegiatan dan permasalahan pelaksanaan.

Gambar 1. Alur Pelaksanaan Dana 


\section{Sumber Pembiayaan promosi kesehatan}

Ada 5 (lima) sumber pembiayaan program promosi kesehatan, yaitu dana APBN, APBD, DAK, bagi hasil pajak dan dana desa pemerintah pusat. Besaran alokasi dana promosi kesehatan ditentukan berdasarkan pengajuan dari Dinas Kesehatan dan ditentukan oleh Pemerintah Daerah. Berikut kutipan pernyataan partisipan:

"Sebenarnya ada banyak sumber dana untuk
promosi kesehatan yang dikemas dalam
beberapa skema, ya...tapi tergantung
pengajuan dari Dinkes setempat ((laki-laki, 60
tahun, Pimpinan)"

Skema biaya promosi kesehatan juga dapat diberikan melalui APBDes (Dana Pemerintah Desa). Program tersebut merupakan program preventif dan promotif yang dilakukan oleh Kader Desa. Dana tersebut dapat di gunakan dengan mekanisme dari Kepala Dukuh ke kepala desa sesuai dengan kegiatan yang akan dilakukan. Berikut kutipan pernyataan partisipan:

"Pemerintah Desa menyediakan dana
kesehatan untuk masyarakat...ya tapi tidak
besar...nanti Pak Dukuh yang akan
mengajukan ke Pemerintah Desa...(Laki-laki,
54 tahun, Pemerintah Desa)"

\section{PEMBAHASAN}

Pandemi COVID-19 merupakan suatu kondisi darurat yang mengancam kehidupan masyarakat (Sankar et al., 2020). Himbauan social dan physical distancing selama pandemic Covid-19 menyebabkan keterbatasan dalam melakukan pemantauan DM. Upaya meningkatkan pengetahuan dan perilaku hidup sehat selama pandemi COVID-19 perlu dilakukan.Berbagai model pemantauan berbasis IT telah dikembangkan dalam memberikan perawatan preventif kepada pasien HT dan DM. Dibeberapa negara maju, pemanfaatan telehealth efektif dalam mengendalikan pasien PTM, termasuk HT dan PTM. Selain murah, model tersebut mudah digunakan oleh pasien (Hossain et al., 2019).

Pasien dapat melakukan pemantauan secara mandiri dengan menggunakan telepon seluler. Few Touch Application (FTA) merupakan salah satu aplikasi yang dikembangkan sebagai salah satu alat untuk memantau hasil pengukuran gula darah sewaktu (GDS) pasien secara berkala. Aplikasi tersebut dapat memberikan motivasi kepada pasien sesuai kebutuhan (Årsand et al., 2010). Selain itu, aplikasi tersebut mennyajikan laporan pola makan dan aktivitas fisik yang sudah dilakukan. Paisen mengisi kebiasaan makan dan aktivitas fisik secara mandiri (Lunde et al., 2018).

Pada tahun 2015-2019 pendanaan pelaksanaan rencana aksi nasional penanggulangan PTM dibebankan pada ABPN, APBD, dan sumber lain yang sah sesuai ketentuan perundang-undangan. Dana Alokasi Khusus (DAK) sebagai salah satu sumber pembiyaan daerah dalam pelaksanaan desentralisasi. Pembiayaan ini untuk mendukung upaya promotif dan preventif dala mencapai Program Indonesia Sehat.

Hasil penelitian ini menjelaskan bahwa alokasi dana yang diajukan di Pemerintah daerah kabupaten Sleman disusun oleh Dinkes yang mengacu pada APBD yang sudah ditetapkan. Dana tersebut ditransfer setiap bulan sesuai rancangan yang disusun oleh Dinkes. Selain itu, ada skema BOK yang merupakan salah satu dana dari DAK Nonfisik Bidang Kesehatan yang digunakan untuk meringankan beban masyarakat terhadap pembiayaan kesehatan, terutama pelayanan di Pusat Kesehatan Masyarakat (Puskesmas).

Pemerintah Daerah telah menetapkan bahwa BOK diutamakan untuk upaya promotif dan preventif. Puskesmas 
menyusun RKA berdasarkan alokasi yang diterima dari Kabupaten atau Kota dan hasil RKA yang dikompilasi oleh Dinkes Kabupaten atau Kota menjadi RKA Dinkes. Rancangan tersebut dibahas dalam RAP dan RAPBD. Pelaksanaan kegiatan DAK Nonfisik Bidang Kesehatan dilaksanakan oleh Dinkes Pemerintah Daerah Provinsi atau Kabupaten atau Kota sesuai kegiatan DAK Nonfisik Bidang Kesehatan masing-masing.

Penelitian sebelumnya menjelaskan bahwa bentuk pemberdayaan masyarakat meminimalkan anggaran yang dikeluarkan Pemerintah. Bentuk pemberdayaan tersebut dengan cara mengikutsertakan anggota keluarga ataupun orang terdekat pasien dalam pengendalian PTM. Keluarga pasien dilibatkan langsung dalam penanganan PTM salah satunya dengan memberikan edukasi kepada keluarga pasien. Keluarga pasien diberikan edukasi terkait kondisi kegawatan yang dialami oleh pasien PTM untuk mengakses pelayanan kesehatan. Edukasi ini penting dilakukan agar dapat membantu pasien dalam mengatasi permasalahan kesehatan. Sehingga, tidak semua pasien yang mengalami keluhan langsung dibawa ke pelayanan kesehatan yang dapat meningkatkan pembiyaan nasional (Kusumo, Hendrartini, Sufro and Dewi, 2020b).

Di beberapa negara maju menyebutkan bahwa pelayanan kesehatan dapat diakses. Kebijakan ini dirancang dalam rangka mengimplementasikan program UHC (universal Health Coverage). Sedangkan dinegara berkembang lebih fokus terhadap kebijakan sosial yang diterapkan secara terintegrasi untuk merealisasikan sinergi antara kesehatan, pendidikan dan perlindungan sosial. Beberapa negara telah berusaha untuk memperkenalkan reformasi pembiayaan kesehatan menuju Universal Health Coverage. Reformasi tersebut perlu mendapatkan sumber-sumber pendapatan yang memadai dan berkelanjutan untuk promosi dan pencegahan kesehatan pada Agenda 2030. Di Thailand biaya promosi kesehatan dan pencegahan penyakit dapat diakses melalui tiga mekanisme yang berbeda dan di dukung oleh pemerintah daerah. Dua dana dari pemerintah berasal dari pajak dan alokasi kapitasi, termasuk pendapatan daerah.Saat ini Thailand telahmemiliki perawatan kesehatan primer yang dinamis, pengembangan sistem kesehatan yang inovatif dan program promosi kesehatan yang progresif. Pemerintah Thailand mengadopsi kebijakan terkait promosi yang mengarah pada pembentukan badan pemerintah otonom. Kebijakan ini ditampung dalam suatu wadah yang disebut dengan the Thai Health Promotion Foundation (ThaiHealth). Beberapa program dari Thaihealth adalah sekolah dengan diet sehat, pengurangan alkohol dan kampanye aktivitas fisik. Aktivitas fisik meruapakan salah satu upaya yang dapat mengurangi prevalensi PTM. Selain itu, pemanfaatan ThaiHealth dapat menjadi solusi dalam pengendalian PTM khususnya pada daerah yang sulit mengakses layanan kesehatan (Kusumo, 2021). ThaiHealth melaporkan bahwa persentase orang yang mengkonsumsi 2001 menjadi $18.2 \%$ pada tahun 2014 . melakukan aktifitas fisik dengan intensitas sedang selama 150 menit atau 75 menit latihan aerobic intensitas tinggi per minggu meningkat dari $66.3 \%$ pada tahun 2012 menjadi $72.9 \%$ pada tahun 2017.

Mekanisme pendanaan ThaiHealth ini dilakukan melalui pendanaan khusus, transparan, akuntabel serta adanya keterlibatan organisasi masyarakat sipil dan lembaga pemerintahan lainnya yang mendukung. ThaiHealth melalui pergerakan sosial, keterlibatan politik dan bukti ilmiah memiliki beberapa strategi diantaranya mendukung penelitian kebijakan, pemantauan dan implementasi kebijakan promosi kesehatan, tembakau menurun dari $22.5 \%$ pada tahun Persentase penduduk dewasa yang 
mempromosikan kemitraan multisectoral, organisasi masyarakat sipil dan masyarakat, memperkuat dan orientasi ulang komunitas untuk melakukan pencegahan penyakit tidak menular dan mendukung advokasi kebijakan serta kampanye publik secara luas (Pongutta et al., 2019).

Di inggris $9,7 \%$ pendapatan domestik bruto dari anggaran negara untuk masalah kesehatan. Upaya promosi kesehatan tersebut telah di mulai dari rumah sakit, tempat sekolah, tempat kerja serta menciptakan kota yang sehat. Inggris sendiri memiliki lembaga khusus yang bertujuan untuk meningkatkan promosi kesehatan dimasyarakat, namun lembaga ini sudah melebur bersama dengan pemerintah daerah semenjak tahun 2010. Berdasarkan hasil wawancara diketahui bahwa strategi alokasi biaya promosi kesehatan di Indonesia masih memiliki prosedur yang rumit dan masih memerlukan alur yang jelas. Salah satu strategi yang dapat dilakukan adalah menjadikan promosi kesehatan menjadi bagian yang fokus dalam menanggulanggi DM. Salah satunya melalui pembentukan badan khusus yang mengacu pada Thaihealth dengan mengelola promosi kesehatan melalui pembentukan kebijakan, berintegrasi dengan lembaga lain melalui advokasi, maupun penelitian (Watabe et al., 2017). Di Iran salah satu sumber biaya promosi kesehatan berasal dari pajak. Selain dari pajak, sumber promosi kesehatan yang digunakan oleh Pemerintah Iran berasal dari asuransi sosial dan alokasi dana yang bersumber dari Pemerintah Iran (Javadinasab et al., 2019).

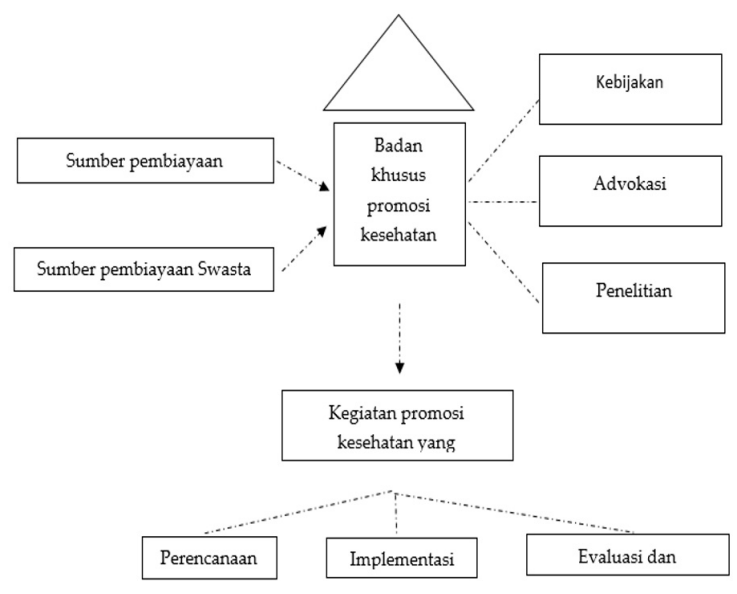

Gambar 2. Strategi penanggulangan DM

Sumber: (Watabe et al., 2017)

Satu penyebab masih tingginya prevalensi DM adalah belum berjalannya program preventif dan promotif. Rendahnya proporsi belanja kesehatan yang dianggarkan oleh Pemerintah Indonesia menjadi penyebab utama tidak berjalannya berbagai program prefentif dan promotif. Beberapa penelitian sebelumnya menjelaskan bahwa perlu adanya intervensi yang fokus pada perubahan gaya hidup untuk mencegah DM. Intervensi tersebut lebih cost-effective dibandingkan dengan intervensi lainnya (Radl et al., 2013). Intervensi melalui olahraga dan konseling gaya hidup tersebut dapat meningkatkan status kesehatan pasien DM (Sultana et al., 2015). Hasil penelitian tersebutdiperkuat dengan penelitian sebelumnya yang fokus pada program diet dan aktivitas fisik untuk mencegah peningkatan risiko DM (Li et al., 2015). Penelitian sebelumnya juga menjelaskan bahwa pencegahan DM melalui aktivitas fisik dan atau diet terbukti cost effective terhadap pencegahan DM (Alouki et al., 2016). Intervensi diet dan olahraga dapat dimanfaatkan pasien tanpa tambahan biaya. Berbeda dengan intervensi yang bertujuan untuk kepatuhuan minum obat yang membutuhkan personel terlatih (Nerat et al., 2016). Berbagai intervensi tersebut dapat menurunkan risiko kardiovaskuler dalam follow-up satu tahun. Implementasi 
intervensi gaya hidup sehat tersebut akan mengurangi biaya kesehatan yang harus dikeluarkan untuk pengobatan (JacobsVan Der Bruggen et al., 2009). Selain itu, promosi kesehatan berbasis pemberdayaan masyarakat dan budaya lokal juga berkontribusi terhadap penurunan prevalensi DM. Biaya yang murah dan mudah dilakukan menjadi pilihan untuk menerapkan intervensi ini (Kusumo, Hendrartini, Sufro and Tetra, 2020). Program bertujuan untuk melatih pasien DM agar mampu mengendalikan glukosa darah secara mandiri (Susilo, Kusbaryanto and Kusumo, 2021).

Kementrian Kesehatan dan BPJS Kesehatan merancang Program Prolanis untuk mengendalikan DM. Program tersebut mendorong pasien lebih proaktif yang melibatkan peserta, fasilitas kesehatan dan BPJS Kesehatan. Alokasi dana untuk kegiatan tersebut maksimal Rp. $\quad 970.000$ setiap bulan (Badan Penyelenggara Jaminan Sosial, 2014). Selain itu,ada DAK yang bersumber dari APBN dialokasikan untuk kegiatan preventif dan promotif. Alokasi ini disalurkan melalui skema Dana BOK). Kementerian Kesehatan menetapkan total alokasi BOK puskesmas per kabupaten atau kota yang ditetapkan oleh dinas kesehatan (Kementrian Kesehatan Republik Indonesia, 2019).

World Health Organization (WHO) melaporkan bahwa proporsi belanja kesehatan terhadap APDB Indonesia masih di bawah rata-rata negara berpenghasilan rendah hingga menengah, yaitu 2,8\% dari APBD (2,2\%) (WHO, 2017). Kondisi ini diakibatkan oleh rendahnya kontribusi pemerintah terhadap pembiayaan kesehatan, walaupun sejak tahun 2004 anggaran tersebut meningkat secara signifikan. Alokasi yang dianggarkan pemerintah minimal 5\% dari total APBN, sedangkan untuk APBD, alokasi untuk kesehatan minimal 10\%. Berdasarkan persyaratan tersebut, pemerintah akan meningkatkan alokasi anggaran untuk perawatan kesehatan secara nasional menjadi 5\% dari total anggaran pemerintah pada tahun 2016 (WHO, 2017).

Rata-rata negara berpenghasilan rendah sampai menengah hanya mengeluarkan sampai dengan $11 \%$ biaya kesehatan. Meskipun 93\% dari beban penyakit secara global sekitar $84 \%$ (Preker et al, 2000). Pada tahun 2010, The Thailand Health Promotion Fundation (ThaiHealth) membiayai kegiatan promosi dan pencegahan penyakit sekitar $10,8 \%$ dari total seluruh biaya kesehatan. Persentase ini lebih besar dibandingkan dengan negara berpenghasilan menengah yaitu antara 7-9,2\% : (Watabe et al., 2017).

\section{PENUTUP}

\section{Kesimpulan}

Ada 3 (tiga) skema alokasi biaya promosi kesehatan yang dapat digunakan untuk mengendalikan DM di kabupaten sleman. Skema tersebut dikelompokkan berdasarkan sumber dana yang digunakan, yaitu sumber dana yang berasal dari Pemerintah Pusat, Pemerintah Daerah, dan Pemerintah Desa.

\section{Saran}

Diperlukannya sistem yang terintegrasi antara penerima layanan kesehatan, Pemerintah Desa, Pemerintah Daerah, dan Pemerintah Pusat dalam menggunakan dana kesehatan untuk mengendalikan DM.

\section{DAFTAR PUSTAKA}

Alouki, K. et al. (2016) 'Lifestyle Interventions to Prevent Type 2 Diabetes: A Systematic Review of Economic Evaluation Studies', Journal of Diabetes Research, 2016. doi: 10.1155/2016/2159890.

Årsand, E. et al. (2010) 'Mobile phonebased self-management tools for type 2 diabetes: The few touch application', Journal of Diabetes Science and Technology, 4(2), pp. 328-336. doi: 
10.1177/193229681000400213.

Badan Penyelenggara Jaminan Sosial (2014) Panduan praktis PROLANIS (Program pengelolaan penyakit kronis), Healthcare and Social Security Agency. Jakarta, Indonesia: BPJS.

Dinas Kesehatan Provinsi DIY (2013) Profil Kesehatan Daerah Istimewa Yogyakarta 2013, ... Health Care. doi: 10.1017/ CBO9781107415324.004.

Epstein, L. H. and LaPorte, R. E. (2016) Behavioral epidemiology, Behavior Therapist.

Grover, A. and Joshi, A. (2015) 'An overview of chronic disease models: a systematic literature review', Global journal of health science, 7(2), pp. 210227. doi: $10.5539 / g j h s . v 7 n 2 p 210$.

Hossain, M. M. et al. (2019) 'Digital interventions for people living with non-communicable diseases in India: A systematic review of intervention studies and recommendations for future research and development', Digital Health, 5, pp. 1-18. doi: 10.1177/2055207619896153.

Jacobs-Van Der Bruggen, M. A. M. et al. (2009) 'Cost-effectiveness of lifestyle modification in diabetic patients', Diabetes Care, 32(8), pp. 1453-1458. doi: $10.2337 /$ dc09-0363.

Javadinasab, H. et al. (2019) 'Sustainable financing of health promotion services in selected countries: Best experience for developing countries', Medical Journal of the Islamic Republic of Iran, 33(1). doi: 10.34171/mjiri.33.52.

Kementrian Kesehatan Republik Indonesia (2019) 'PERATURAN MENTERI KESEHATAN REPUBLIK INDONESIA NOMOR 3 TAHUN 2019'. Jakarta, Indonesia: Kementrian Kesehatan Republik Indonesia, pp. 323.

Kusumo, M. P., Hendrartini, J., Sufro, Z. M. and Dewi, F. S. T. (2020a) 'A qualitative study to explore the perception of patients towards diet in Javanese culture', Enfermeria Clinica,
30(October), pp. 183-187. doi: 10.1016/ j.enfcli.2020.06.041.

Kusumo, M. P., Hendrartini, J., Sufro, Z. M. and Dewi, F. S. T. (2020b) 'Theater performing art: A strategy to improve self-efficacy and social support in patient with type 2 diabetes mellitus (T2DM)', Journal of Global Pharma Technology, 12(6), pp. 70-76.

Kusumo, M. P., Hendrartini, J., Sufro, Z. M. and Tetra, F. S. (2020) 'Theater Performing Arts ( TPA ): Community Empowerment to Improve Blood Glucose Control Behavior in Yogyakarta', 18(4). doi: 10.5812/ ijem.103106.Research.

Kusumo, M. P. (2021) 'Physical Activity Patterns in Lecturers During Covid-19 Pandemic: A Qualitative Study', JMMR (Jurnal Medicoeticolegal dan Manajemen Rumah Sakit), 10(1), pp. 3842. doi: 10.18196/jmmr.v10i1.10829.

Li, R. et al. (2015) 'Economic Evaluation of Combined Diet and Physical Activity Promotion Programs to Prevent Type 2 Diabetes Among Persons at Increased Risk: A Systematic Review for the Community Preventive Services Task Force.', Annals of internal medicine, 163(6), pp. 452-60. doi: 10.7326/M15-0469.

Lunde, P. et al. (2018) 'The effectiveness of smartphone apps for lifestyle improvement in noncommunicable diseases: Systematic review and metaanalyses', Journal of Medical Internet Research, 20(5), pp. 1-12. doi: 10.2196/ jmir.9751.

Nerat, T., Locatelli, I. and Kos, M. (2016) 'Type 2 diabetes: Cost-effectiveness of medication adherence and lifestyle interventions', Patient Preference and Adherence, 10(November 2017), pp. 2039-2049. doi: 10.2147/PPA.S114602.

Pongutta, S. et al. (2019) 'Lessons from the thai health promotion foundation', Bulletin of the World Health Organization, 97(3), pp. 213-220. doi: 10.2471/BLT.18.220277. 
Radl, K. I., Ianuale, C. and Boccia, S. (2013) 'A systematic review of the costeffectiveness of lifestyle modification as primary prevention intervention for diabetes mellitus type 2', Epidemiology Biostatistics and Public Health, 10(2), pp. 1-8. doi: $10.2427 / 8846$.

RISKESDAS (2018) Prevalensi Diabetes Mellitus di Indonesia. Jakarta, Indonesia.

Sankar, J. et al. (2020) 'COVID-19 in Children: Clinical Approach and Management', The Indian Journal of Pediatrics. The Indian Journal of Pediatrics, p. 1. doi: https://doi.org/ 10.1007/s12098-020-03292-1.

Siminerio, L., Zgibor, J. and Solano, F. X. (2004) 'Implementing the Chronic Care Model for Improvements in Diabetes Practice and Outcomes in Primary Care: The University of Pittsburgh Medical Center Experience', Clinical Diabetes, 22(2), pp. 54-58. doi: 10.2337/diaclin.22.2.54.

Sultana, F., Srilekha, S. and Soumendra, S. (2015) 'Cost effectiveness of exercise intervention and lifestyle counselling in prevention and control of diabetes mellitus-a review', International Journal of Pharma and Bio Sciences, 6(4), pp. B566-B576.

Susilo, D. H., Kusbaryanto, K. and Kusumo, M. P. (2021) 'Diabetes Mellitus Management during the Coronavirus disease-19 Pandemic: Literature Review', 9, pp. 541-548.

Watabe, A. et al. (2017) 'Analysis of health promotion and prevention financing mechanisms in Thailand', Health Promotion International, 32(4), pp. 702710. doi: 10.1093/heapro/daw010.

WHO (2010) 'Global status report on noncommunicable diseases 2010', World Health, p. 176. doi: 978924 1564229.

WHO (2017) The Republic of Indonesia Health System Review. Edited by U. of M. Krishna Hort, Nossal Institute for Global Health and M. of P. H. T. Walaiporn Patcharanarumol, International Health Policy Program. Indonesi.

Wild, S. et al. (2004) 'Global Prevalence of Diabetes: Estimates for the year 2000 and projections for 2030', Diabetes Care, 27(5), pp. 1047-1053. doi: 10.2337/ diacare.27.5.1047. 